\title{
HACIA UN HOSPITAL SIN LÁTEX
}

\author{
PAZ URIBE LLOPIS, PILAR BARBERO DEL PALACIO, Ma TERESA ALONSO COBO, \\ IGNACIO BARDÓN FERNÁNDEZ- PACHECO, Mª COVADONGA CASO PITA
}

\author{
Unidad de Gestión Clínica de Prevención de Riesgos Laborales, Área 7 \\ Hospital Clínico San Carlos. \\ Madrid
}

\section{RESUMEN}

El objetivo principal de este trabajo es, describir los pasos que se han dado en un hospital público para ir "Hacia un Hospital sin Látex".

El aumento de la prevalencia de las enfermedades alérgicas, nos lleva a realizar una serie de actuaciones englobadas dentro de una política hospitalaria para disminuir la presencia de látex en el hospital. Con ello, queremos conseguir disminuir la alergia al látex de los trabajadores y evitar en los pacientes especialmente sensibles las posibles reacciones alérgicas al ser intervenidos quirúrgicamente.

\section{PALABRAS CLAVES}

Alergia Látex. Hospital. Procedimiento de actuación. Intervención Quirúrgica Programada. Trabajadores. Pacientes.

\section{ABSTRACT}

The main objective of this work is to describe the steps that hand been given in a public hospital in order to go "Towards a hospital without latex".

The increasing of allergy illness is the reason because of that; we have to make a number of actions in a hospitable policy, with the purpose of decreasing the latex content in the hospital.

With theses actions we want to get a latex allergy decreasing in the workers avoiding in the sensitive patients the possible allergy reactions when they are performed an operation.

\section{KEY WORDS}

Latex allergy, Hospital, Procedure of actions, planned operation, Workers, Patients. 


\section{INTRODUCCIÓN}

Las enfermedades alérgicas son afecciones resultantes de una respuesta inmunológica alterada que se produce por una hipersensibilidad frente a antígenos diversos (alérgeno-factor ambiental) en pacientes especialmente predispuestos (factor genético).

La prevalencia de las enfermedades alérgicas se encuentra en aumento en todo el mundo, especialmente en el mundo occidental. Este aumento es debido a causas no muy bien aclaradas en la actualidad, entre ellas la exposición a nuevos antígenos es una de las posibilidades que se apunta como factor principal de riesgo.

La primera descripción de alergia al látex se realiza en el año 1927. En la década de los 90, comienzan a aparecer más y más casos que se asocian con la exposición a este producto, hablándose de "epidemias de alergia al látex", dado el aumento en el uso de guantes de látex como prevención del contacto de nuevas enfermedades infecciosas. Aunque la exposición al látex se puede producir en cualquier lugar, es indudable que en los hospitales se producen las reacciones mas graves.

\section{EPIDEMIOLOGÍA}

La prevalencia auténtica de alergia al látex no se conoce exactamente. Es cierto que antes de los años $80 \mathrm{su}$ frecuencia era muy baja, pero a partir de esa fecha comienzan a realizarse en diferentes países estudios epidemiológicos en diferentes grupos de población, estudios que presentan diferencias en la prevalencia no solo según el grupo estudiado, sino también según el país del que procede el trabajo científico.

Los primeros trabajos realizados por Turjanma y Moneret-Vautin, a finales de los 80 establecieron la prevalencia de alergia al látex en menos del $1 \%$ en población general. Posteriormente Vanderoplas aumenta esta sensibilización hasta el $6,6 \%$ en poblaciones similares.

La mayor parte de los cuadros de alergia al látex se desarrollan en grupos de población bien definidos cuyo único nexo en común es la mayor exposición al látex, lo que parece un factor muy importante en el desarrollo de este tipo de alergia. Estos grupos están constituidos por:
- Trabajadores sanitarios. En este grupo las cifras de trabajadores alérgicos al látex varía entre 2,6 al $16,9 \%$, siendo mayor la probabilidad de los trabajadores del quirófano donde la exposición es netamente superior. Las estadísticas varían de unos estudios a otros debido a la diferente protocolización diagnóstica, y es importante reseñar que la tercera parte de los casos declarados se corresponden con reacciones de hipersensibilidad tipo IV es decir, dermatitis de contacto o irritativas que en algunos casos se corresponden casi con el $24 \%$ de las sensibilizaciones descritas.

Un estudio epidemiológico realizado en nuestro hospital resultó en una frecuencia de sensibilización al látex del 12,5\%, observándose que hasta el $30 \%$ de los pacientes sensibilizados presentaban sensibilización a otros alérgenos.

- Pacientes con anomalías urogenitales y multioperados. Este grupo de riesgo lo constituyen en especial niños con espina bífida y con defectos urogenitales que requieren múltiples operaciones y sondajes de repetición. Se estima la prevalencia de sensibilización en estos pacientes entre el $10 \%$ y el $60 \%$ según las diferentes series estudiadas.

- Población alérgica a frutas tropicales. Tras la descripción de Carrillo y colaboradores del síndrome de látex-frutas se ha observado que la sensibilización al látex es más alta en esta población que en población general e incluso se multiplica por 24 si se presenta alergia a determinadas frutas como aguacate o castaña.

\section{MANIFESTACIONES CLÍNICAS}

La patología producida por la hipersensibilidad al látex es muy variable, estando condicionada por la ruta de exposición, la cantidad de alérgeno contactado y factores individuales. Las manifestaciones clínicas se deben a la exposición de un producto de caucho natural cuyos antígenos se transfieren al paciente sensibilizado por contacto directo o por vía aérea, siendo difícil distinguir la contribución relativa a los síntomas de una u otra (contacto directo o por vía aérea). 
Los síntomas y signos que pueden presentar los pacientes alérgicos al látex pueden ser localizados o generalizados, consistiendo en cualquier combinación de: urticaria local/regional/generalizada, angiodema, rinitis, conjuntivitis, asma y/o schock anáfiláctico. Los síntomas pueden aparecer de forma progresiva desde una urticaria leve hasta una anafilaxia grave o bien mantenerse estables a lo largo del tiempo, sin que se pueda predecir la historia natural para cada paciente. Los síntomas aparecen desde escasos minutos a una hora tras la exposición. La exposición mucosa o parenteral, conlleva mayor riesgo de anafilaxia. La exposición cutánea o respiratoria ocasionalmente provoca reacciones sistémicas graves.

\section{MATERIAL Y MÉTODOS}

\section{Actuaciones para ir hacia un hospital sin látex.}

En el año 1999 el Servicio de Prevención de Riesgos Laborales inicia un procedimiento de actuación ante los trabajadores alérgicos al látex. El trabajador que acude a la consulta de Vigilancia y Control de la Salud por sospecha de alergia al látex es remitido a la consulta del Servicio de Alergia para confirmar o no la misma. Durante el estudio, el Servicio de Prevención dota a los trabajadores de guantes de vinilo para tareas no estériles y guante de neopreno para tareas estériles. Lo datos del trabajador una vez confirmada la alergia al látex son introducidos en una base de datos y el Servicio de Prevención le sigue dotando de los guantes correspondientes.
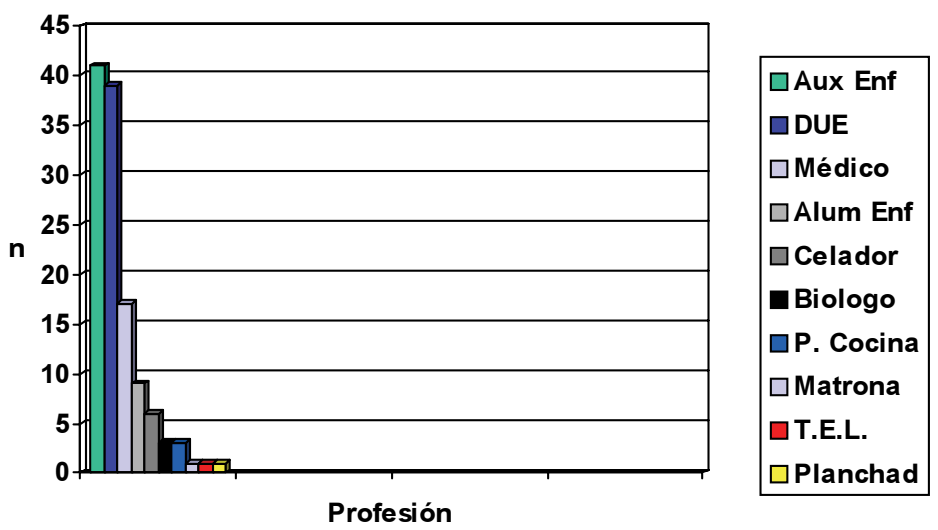

Figura 1. Trabajadores con alergia al látex. Distribución por profesión $(N=121)$.
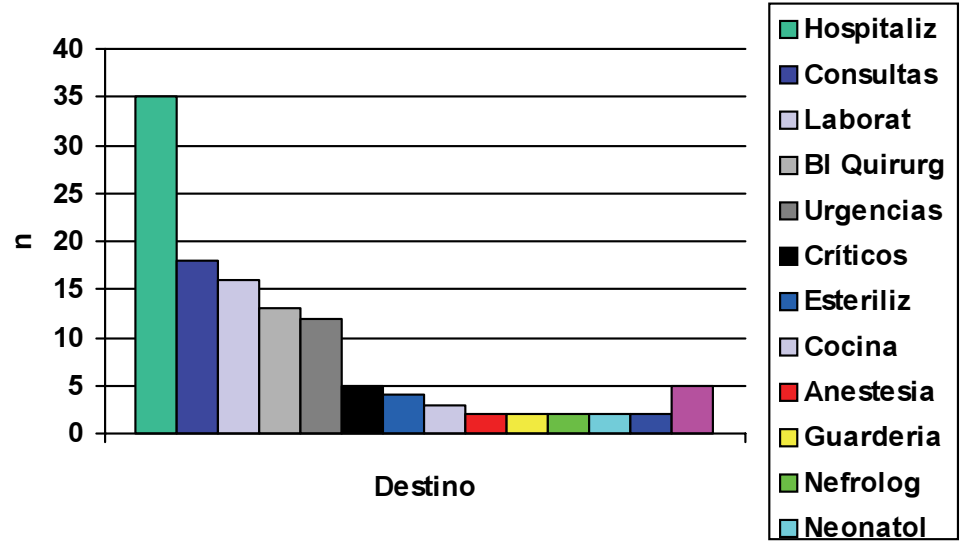

Figura 2. Trabajadores con alergia al látex con alergia al látex. Diostribución por destino (N=121). 


\section{Base de datos de trabajadores con alergia al látex, Servicio de Prevención}

En el sistema de registro de nuestro hospital, hay 121 casos con una prevalencia del 2,2\% y con una adecuación de puesto de trabajo de 7 casos.

Dentro de una política de disminución de presencia de látex en el hospital, en el año 2004 se establecen una serie de actuaciones:

- Introducción de guantes de vinilo en todo el hospital, para tareas cortas y de bajo riesgo biológico, sin contacto prolongado con fluidos y con frecuencia de cambio entre 10 a 15 minutos.

- Introducción de guantes de nitrilo en determinadas áreas donde teníamos trabajadores alérgicos al látex. Estos guantes son para tareas más largas y contacto con fluidos prolongados $\mathrm{y}$ con frecuencia de cambio entre 15 o 30 minutos.

- Guantes de examen (no estéril) de látex sin polvo: es introducida una partida en el año 2006 y se esperan introducir en su totalidad en el presente año 2007.

- Política de compra de material sanitario exento de látex a comienzos del año 2005.

- En el año 2004 se comienza la elaboración de un procedimiento de actuación ante el paciente alérgico al látex en intervenciones quirúrgicas programadas que finaliza en el 2005.

\section{Política actual de guantes en el hospital.}

- Guantes de vinilo: en todo el hospital

- Guantes de látex de examen no estériles con y sin polvo: en todo el hospital

- Guantes de nitrilo no estériles: en determinadas áreas donde hay trabajadores alérgicos al látex y áreas de manejo de citostáticos.

- Guantes estériles de neopreno con polvo y poliisopreno sin polvo: dotación por el Servicio de Prevención a trabajadores alérgicos al látex.
Procedimiento de actuación ante el paciente alérgico al látex en intervenciones quirúrgicas programadas.

1. La realización del procedimiento fue encomendado a los Servicios de Prevención y de Alergia, por parte del Presidente de la Comisión de Riesgos Hospitalarios. Estos dos Servicios, crean un grupo de trabajo constituido por profesionales de otros Servicios implicados (Dirección de Enfermería, Farmacia etc.).

Para la realización del procedimiento fue necesario:

- Establecer un circuito del paciente durante su estancia en el hospital y se determinan las actuaciones requeridas tanto de los espacios físicos (habitación, críticos I, quirófanos, etc.), como de los profesionales que atiendan al paciente.

- Revisión de diferentes bases de datos, seleccionando la evidencia científica de las medidas terapéuticas y preventivas, clasificándolas en niveles de riesgo.

- Realización de un diagrama de flujo del paciente y se establecieron hojas de verificación del cumplimiento del procedimiento y del estocaje del material L/L.

- Por ultimo se mantuvieron reuniones con la Coordinadora de la Unidad de Calidad, con el fin de establecer los criterios de calidad para que el "Procedimiento" fuese aprobado por la Comisión del Hospital de Protocolos y Vías Clínicas. También se realizó evaluación de la Estructura, del Proceso y de Efectividad del Procedimiento con diversos indicadores establecidos para el control de calidad del cumplimiento del procedimiento.

2. El objetivo es la realización de un "Procedimiento de actuación para pacientes alérgicos al látex que acuden al hospital para intervención quirúrgica programada" y posteriormente se irán estableciendo otros objetivos :

- Establecer un procedimiento de actuación para pacientes alérgicos al látex que acuden al hospital al Servicio de Urgencias. 
- Establecer un procedimiento de actuación para pacientes alérgicos al látex que acuden al hospital a las diferentes consultas ambulatorias, sobre todo en aquellas que se realicen exploraciones especiales.

Estos dos últimos objetivos se irán consiguiendo en revisiones posteriores del procedimiento, tal y como está establecido en el mismo.

3. La aplicación del procedimiento tiene una clara repercusión en la política de un hospital sin látex, disminuyendo el riesgo de reacciones alérgicas tanto en pacientes que tengan que ser intervenidos quirúrgicamente, como en trabajadores del hospital especialmente sensibles al látex.

\section{PROCEDIMIENTO}

Para la identificación del paciente alérgico al látex que acude al hospital para actuaciones quirúrgicas programadas será imprescindible aportar informe clínico de un Servicio de Alergología, que el paciente presentará en la consulta de Preanestesia. Si el paciente procede de otra área sanitaria la Unidad de Preanestesia, comunicará telefónicamente ó realizará interconsulta con el servicio de Alergología para establecer los requisitos de cuidados que procedan en cada persona, El centro peticionario hará constar en la petición la condición de "paciente alérgico al látex". En caso de haber sido realizado en el Servicio de nuestro centro, desde el Servicio de Admisión se comunicará telefónicamente el ingreso y se enviarán los datos del paciente y copia del informe.

La unidad de Preanestesia comunicará al Servicio de Admisión la antedicha condición para que conste en la ficha del paciente de forma que siempre exista constancia de la misma.

Una vez identificado en el Servicio de Admisión, el paciente alérgico al látex, éste Servicio deberá:

1. Programar la intervención del paciente para un lunes.

2. Contactar con la Supervisora General correspondiente, responsable de la activación del protocolo con tiempo suficiente para iniciar la programación. La responsable de la activación del protocolo podrá delegar en cada una de las loca- lizaciones libres de látex (L/L), que forman parte del protocolo, para su total adecuación en el momento del ingreso del paciente.

3. El Servicio de Admisión deberá emitir las correspondientes identificaciones de:

- puerta habitación

- puertas quirófano preparado

- cama paciente

- cinta muñeca paciente

- historia clínica

- hojas de enfermería

4. Actuación del resto de personal implicado:

a. Identificará la habitación asignada como L/L

b. El personal sanitario y no sanitario que acceda a la habitación, deberá en todo momento utilizar indumentaria $\mathrm{L} / \mathrm{L}$ necesaria según la tarea a realizar y previo lavado de manos:

- Pijama L/L

- Bata L/L

- Zapatos libre de látex o en su defecto proteger con calzos.

- Calzos sin látex (calzos quirúrgicos verdes), siempre que se vaya acceder a la habitación.

- Mascarilla sin látex (mascarillas quirúrgicas con cintas) sólo en quirófano, y si se requiere en otras áreas.

- Gorro sin látex (gorro quirúrgico con cintas, sin gomas elásticas), solo en quirófano, y si se requiere en otras áreas.

- El personal sanitario y no sanitario que acceda a la habitación debe de estar formado en el por qué y como deben trabajar con un paciente alérgico al látex.

c. Se informará a los Servicios de Alergia, Hostelería, Dietética, Farmacia, Mantenimiento, peluqueros y otros profesionales implicados.

d. Verificar que todo el material es L/L y que toda la medicación parenteral esté presentada en forma de ampollas de cristal o en viales cuyo tapón esté certificado por el Servicio de Farmacia como no "látex". En su defecto se quitará el tapón (evitar hacerlo frente al 
paciente alérgico y no generar aerosoles) sin pinchar en él.

e. El personal que atienda al paciente debe ser el menor posible, evitando además entradas innecesarias.

f. El acceso de visitas será restringido y con ausencia de látex. En el caso de habitación compartida con un paciente no alérgico, las visitas de éste deberán evitar portar objetos con látex como globos, pulseras, u otros objetos y deberán cubrir el calzado con calzos siguiendo las instrucciones indicadas en el apartado de Uniformidad.

\section{Intervención quirúrgica programada.}

Una vez identificado el paciente alérgico al látex en el Servicio de Admisión se pondrá en marcha el sistema de protocolización con el cumplimiento de los diferentes ítems que se especifican a continuación (evidencia IV).

1. Identificación y preparación de la habitación donde va a ser ingresado el paciente alérgico al látex.

a. La habitación deberá estar disponible para el domingo por la tarde si el paciente ingresa antes de la intervención o para el lunes si ingresa posteriormente.

b. La habitación será preferentemente individual.

c. En caso de más de un paciente alérgico se podría compartir la habitación.

d. Puede plantearse que, el paciente alérgico comparta la habitación con una persona no alérgica, en este caso siempre debe ingresar primero el alérgico. La habitación será preparada según el protocolo $\mathrm{L} / \mathrm{L}$ y se identificará (según el apartado anterior) como $\mathrm{L} / \mathrm{L}$, y se usará el material $\mathrm{L} / \mathrm{L}$ para la asistencia de ambos.

e. En el caso de compartir habitación, el paciente no alérgico será informado de esta circunstancia para que cumpla con el protocolo. f. Sustituir todos los elementos que contengan látex por otros libres de látex o en su defecto, forrarlos o recubrirlos con material aislante (ejemplo: tela, plástico trasparente) que evite la dispersión de partículas de látex.

g. Retirar tapón del lavabo que contiene látex.

h. Asegurar que el colchón y la funda no sean de látex.

i. Asegurar que el sillón no sea de látex y en su defecto proteger con sábanas.

j. Las ruedas de la cama y las patas del sofá deberán protegerse con calzos sin látex $\mathrm{o}$ tubitón.

k. La habitación, (paredes y superficies) será limpiada el día anterior al ingreso por personal de limpieza formado y con equipo de limpieza L/L, será cerrada hasta el día siguiente. La limpieza diaria será realizada por el mismo personal preferiblemente, y sino estará informado y formado y usará el equipo L/L.

1. La habitación tendrá sistema de climatización sin recirculación de aire con otras habitaciones, y si es posible con presión positiva.

m. Todo el material L/L a emplear con el paciente se colocará en una mesa, dentro de la propia habitación.

n. En la puerta de la habitación se pondrá un cartel avisando de la alergia al látex.

o. En el caso de que el paciente necesitara mascarilla de $\mathrm{O}_{2}$, se le quitará la goma ya que contiene látex y se le colocará una venda para sujetarla.

p. Las extracciones de sangre se realizarán con aguja y jeringa exentas de látex, y el relleno de los tubos de análisis correspondientes, se realizará fuera de la habitación ya que estos contienen látex.

2. Adecuación del área prequirúrgica y preparación del personal que deba conducirle al quirófano.

Preparación área prequirúrgica:

(i) Manejo de los pacientes alérgicos al látex. Cinco principios. Cleveland Clinic Fundation. http://www.uam.es/departamentos/medicina/anesnet/gtuae/latexe/5 minute.htm. 
a. Si el paciente ingresa el mismo día de la cirugía, la Supervisora General será la responsable de notificar a la enfermera del área prequirúrgica que el paciente es alérgico al látex.

b. Identificación del paciente alérgico al látex, mediante cinta en la muñeca del paciente, cama, e historia clínica previo paso al quirófano.

c. Asegurar que el colchón y la funda no son de látex.

d. El personal de enfermería que atiende al paciente durante la estancia en esta área, utilizará guantes $\mathrm{L} / \mathrm{L}$ y para el resto de pacientes que estén en la misma sala.

e. Si es necesario aplicar alguna medicación previa a la cirugía, asegurar que el material está $\mathrm{L} / \mathrm{L}$.

3. Identificación y adecuación de quirófano que será utilizado el lunes por la mañana.

a. Sustituir todos los elementos que contengan látex por otros libres de látex o en su defecto, forrarlos o recubrirlos con material aislante (ejemplo: tela, plástico trasparente) que evite la dispersión de partículas de látex.

b. El quirófano será limpiado, (paredes y superficies) un viernes por la tarde y cerrado hasta el día de la cirugía (lunes a primera hora). El quirófano estará debidamente identificado como $\mathrm{L} / \mathrm{L}$ en todos los accesos para que no sea utilizado. El personal de limpieza estará formado y utilizará equipo de limpieza libre de látex.

c. Todo el personal que acceda al quirófano utilizará prendas libres de látex. (ver uniformi$\mathrm{dad})$

d. En caso de tener que poner gorro al paciente, deberá estar exento de látex.

e. Todo el material e instrumental utilizado en la cirugía será $\mathrm{L} / \mathrm{L}$.

f. En el caso de que el paciente necesitara mascarilla de $\mathrm{O}_{2}$, se le quitará la goma ya que contiene látex y se le colocará una venda para sujetarla.
4. Aviso y adecuación de la Unidad de Recuperación Post-Anestesia (URPA) que deberá estar preparada para el control posquirúrgico del paciente.

a. Notificación por parte del quirófano a la URPA de la alergia al látex del paciente.

b. Identificación del paciente alérgico al látex dentro de la unidad.

c. Si fuera posible colocar la cama del paciente en la zona con el menor $n^{\circ}$ posible de pacientes.

d. Asegurar que el colchón y la funda de la cama no sean de látex.

e. El personal de enfermería que atiende al paciente durante la estancia en esta área, utilizará material $\mathrm{L} / \mathrm{L}$, además utilizará guantes libres de látex para el resto de pacientes que estén en la misma sala.

f. En el caso de que el paciente necesitara mascarilla de $\mathrm{O}_{2}$, se le quitará la goma ya que contiene látex y se le colocará una venda para sujetarla.

g. La limpieza diaria de la zona donde esté ubicado el paciente será realizada por personal de limpieza formado y con equipo L/L.

h. Todo el material L/L a emplear con el paciente se colocará en una mesa lo más cercano al paciente.

5. Aviso y adecuación de la habitación CRÍTICOS I que deberá estar preparada para el control posquirúrgico del paciente, en caso de cirugía programada que precise ser ingresado postquirurgicamente.

a. La habitación será preferentemente individual.

b. Sustituir todos los elementos que contengan látex por otros libres de látex o en su defecto, forrarlos o recubrirlos con material aislante (ejemplo: tela, plástico trasparente) que evite la dispersión de partículas de látex.

c. Retirar tapón del lavabo que contiene látex.

d. Asegurar que el colchón y la funda no sean de látex. 
e. Asegurar que el sillón no es de látex y en su defecto proteger con sábanas.

f. Las ruedas de la cama y las patas del sofá deberán protegerse con calzos sin látex $\mathrm{o}$ tubitón.

g. La habitación tendrá sistema de climatización sin recirculación de aire, y si es posible con presión positiva dentro de ella con respecto al pasillo. Para aumentar la presión positiva dentro de la habitación del Servicio Críticos I, es posible que se pueda conseguir, tapando la rejilla de extracción del aire.

h. La habitación será limpiada, (paredes y superficies) el día anterior por personal de limpieza formado y con equipo de limpieza L/L., y estará cerrada hasta el día del ingreso. La limpieza diaria será realizada por el mismo personal.

i. El personal de enfermería que atienda al paciente durante su estancia en esta unidad utilizará material $\mathrm{L} / \mathrm{L}$, además utilizará guantes libres látex para el resto de pacientes que tenga que atender. (Ver uniformidad)

j. Las extracciones de sangre se realizarán con aguja y jeringa exentas de látex, y el relleno de los tubos de análisis correspondientes, se realizarán fuera de la habitación ya que estos tienen látex.

k. En el caso de que el paciente necesitara mascarilla de $\mathrm{O}_{2}$, se le quitará la goma ya que contiene látex y se le colocará una venda para sujetarla.

\section{SERVICIOS O DEPARTAMENTOS IMPLICADOS}

1. Esterilización: Actualmente no se utilizan guantes de látex en la preparación del instrumental para esterilizar. En cualquier caso comprobar que el instrumental que se vaya a utilizar para la cirugía exenta de látex, nunca será preparado con guantes de látex en la central de esterilización, y vigilando estrechamente que dicho instrumental no contenga látex.

La caja de instrumental una vez esterilizada, se colocará en el quirófano preparado L/L el día anterior a la cirugía.
2. Farmacia: Se avisará al Servicio de Farmacia del ingreso del paciente alérgico al látex, para que expendan la medicación $\mathrm{L} / \mathrm{L}$ al paciente $\mathrm{o}$ en su defecto comuniquen que el envase lleva látex para que la enfermería siga las pautas según protocolo. Ajustarse a las recomendaciones del Servicio de Farmacia.

3. Hostelería: Los menús del paciente serán preparados de forma individual, y durante todo el proceso de preparación el personal de hostelería no utilizará guantes de látex (usar vinilo). El menú del paciente se preparará según ordenes estrictas del Servicio de Dietética.

4. Dietética: Los menús que deban ser servidos a los pacientes alérgicos al látex serán cuidadosamente elegidos atendiendo a las posibles sensibilizaciones del paciente, ya que puede sufrir un síndrome látex - frutas. Se tendrá especial cuidado con castañas, plátanos, kiwis, aguacates y otras frutas tropicales que en el $90 \%$ de los casos presentan reactividad cruzada. Algunos pacientes no toleran las solanáceas: patata y tomate. Ocasionalmente algunas frutas de uso habitual producen aumento de los síntomas. Por ejemplo las rosáceas: manzana, cereza, melocotón, ciruelas, almendra o similares. Por ello las comidas serán sencillas no muy elaboradas. Se tendrá en cuenta que muchos postres, incluidos lácteos: yogures, mousse de yogur o queso, llevan en su composición este tipo de alimentos. (En ocasiones son sólo saborizantes, pero debe comprobarse en el etiquetado).

Se comprobará previamente con el paciente y el Servicio de Alergia la idoneidad de la composición de la dieta.

5. Peluqueros: En caso de tener que rasurar al paciente todo el material será libre de látex.

- Maquinillas de afeitar de un solo uso de plástico (de uso en el hospital).

- Guantes de vinilo.

- Esponja (de uso en el hospital). 
6. Traslado del paciente: El traslado del paciente alérgico al látex a través del hospital ( $R x$, pruebas, etc.) se realizará siempre por el trayecto más corto y si fuera posible se le colocará una mascarilla de protección respiratoria (FFP1,) para evitar la posible entrada de partículas de látex.

7. Sistema de climatización: se consultará con el Servicio de Mantenimiento para que determine si hay presión positiva, y no recirculación de aire en la habitación donde se va a encontrar el paciente, con otras dependencias con látex.

8. Personal sanitario: Los cirujanos, anestesistas, intensivistas, enfermeras etc., que tengan que tratar al paciente alérgico al látex deberán estar informados previamente.

9. Personal de limpieza: Estará prohibido el uso de mopas, cepillos y escobas. Todo el material estará libre de látex $\mathrm{L} / \mathrm{L}$ :

- Cubo de plástico.

- Recogedor de plástico.

- Fregona.

\section{ANEXOS DEL PROCEDIMIENTO}

- Relación de productos sin látex en el hospital.

- Stock $3^{a}$ norte. Hospitalización.

- Stock Bloque quirúrgico $5^{\mathrm{a}}$ norte.

- Material de anestesia sin látex. Bloque Quirúrgico $5^{\mathrm{a}}$ norte.

- Material de cirugía laparoscópica sin látex.

- Recomendaciones para la utilización de medicamentos (Farmacia).

\section{RESULTADOS}

En abril del año 2006 se introduce el "Procedimiento" en la Intranet del Hospital, dentro de la sección de Guías y Protocolos del Hospital Clínico para que su difusión alcance a todos los profesionales del hospital.

\section{CONCLUSIONES}

Es importante destacar, que las actuaciones realizadas en el Hospital Clínico San Carlos, van encaminadas a ir poco a poco pero de una manera firme hacia un hospital sin látex.

$1^{\circ}$. La adquisición por parte del hospital de material sin látex si esto es posible.

$2^{\circ}$. La política de actuación desde el Servicio de Prevención ante los trabajadores alérgicos al látex.

$3^{\circ}$. La puesta en marcha en nuestro centro del "Procedimiento de Actuación para pacientes alérgicos al látex que acuden al hospital para intervención quirúrgica programada".

\section{AGRADECIMIENTOS}

A la Dra. C. Martínez Cócera (Jefe del Servicio de Alergia, del Hospital Clínico San Carlos) y al Dr. F. Cruzet (Jefe del Servicio de Prevención, del Hospital Clínico San Carlos. Jubilado actualmente), los verdaderos impulsores en el hospital de las medidas adoptadas.

A la Dirección de Enfermería del Hospital y al Servicio de Admisión por el grado de implicación en la puesta en marcha del "Procedimiento de Actuación para pacientes alérgicos al látex que acuden al hospital para intervención quirúrgica programada". 


\section{BIBLIOGRAFÍA}

Ownby DR, Tomlanovich; Sammons N, McCulloug J. Anaphylaxis associated with latex allergy during barium enema examinations. Am J Roentgenol 1991; 156: 903-8.

Thompson RL. Educational challenges of latex protein allergy. En: Fink J editor. Latex allegy. Philadelphia: Saunder. Immunol Allergy Clin North Am 1995; 15: 159-74.

Quirce Gancedo S, Conde-Salazar Gómez L. Obtención y procesamiento del caucho natural. En Alergia al Látex. Cap. I. Pag.: 11-25. Ed. MRA. Barcelona 2002.

Domínguez Ortega J.,. Martínez-Cócera C, Bartolomé J.M. Alergia al Látex. En Guía de Alergia para Residentes y Atención Primaria. Ed. Diaz-Santos. Madrid 2001. Cap. 12. Pag.: 185-194.

A. Plaza Díaz, J. Domínguez Ortega, A. Alonso Llamazares, T. Robledo Echarrren, M. Cimarra Álvarez-Lovel, J.M. Bartolomé Álvarez, C. Martínez-Cócera. Frecuencia de sensibilización al látex en una consulta de Alergología. Alergol Inmunol Clin 2000. 15 (Supl 2):74.

P. Agustín Ubide, A. Castellano Bravo,D. Guimaraes*, J. Bartolomé Álvarez A. Alonso Llamazares, M. Carballo Martín, L. Zayas Romero, C. Martínez Cócera. Prevalencia de sensibilización al látex en 100 donantes de sangre. Alergol Inmunol Clin 1998. 13(Supl): 290.

Merret T, Merret J, Kekwick R. The prevalence of Immunoglobulin $E$ antibodies to the proteins of rubber (Hevea brasiliensis) latex and grass (Phleum Pratense) pollen in sera of British blood donors. Clin Exp Allergy 1998; 29: 1572-8.
Carrillo Díaz T, Figueroa Rivero J, Navarro Déniz L, Ortega Rodríguez N, Epidemiología y factores de riesgo de la alergia al látex. En Alergia al Látex. Cap. V. Pag.: 85-97. Ed. MRA. Barcelona 2002.

Martínez-Cócera C, Castellano A, Robledo T. Sensibilización a Látex en Ambiente Sanitario: Manifestaciones Clínicas más Frecuentes. MAPFRE Medicina 1998.

A. Castellano Bravo, C. Martínez Cócera,T. Robledo Echarren, A. Alonso Llamazares, M. Cimarra Álvarez, M. Chamorro Gómez, Prevalencia de sensibilización al látex en la población sanitaria. Alergol Inmunol Clin 1998. 13(Supl) 290

Cremer R, Hoppe A, Korsch E, Kleine-Diepenbruck U, Blaker F. Natural rubber latex allergy: prevalence and risk factors in patients with spina bifida compared with atopic children and controls. Eur J Pediatr 1996; 157: 13-6.

Petersen A, Vieths S, Aulepp H, et al. Ubiquitous structures responsible for cross-reactivity between tomato fruit and grass pollen allergen. J Allergy Clin Immunol 1996; 98: 805-15.

SEPAR. Medidas preventivas en el ámbito sanitario de la patología al látex. Sociedad española de neurología y cirugía torácica, año 2003.

Protocolo de adecuación del material anestésico - quirúrgico para pacientes alérgicos al látex. Servicio de alergia y neurocirugía del Hospital Ramón y Cajal de Madrid. Revista Española alergo inmunol clin, febrero 99.

Manejo de los pacientes alérgicos al látex. Cinco principios. Cleveland Clinic Fundation. http://www. uam.es/departamentos/medicina/anesnet/gtuae/latexe/5 minute.htm. 